\title{
Study on Multimedia Art Teaching Resources Management System based on Internet Technology
}

\author{
Bao Quan Pan \\ College of Fine Arts, Beihua University, Jilin City, China
}

\begin{abstract}
The main technical architecture of art teaching management system was developed on $\mathrm{B} / \mathrm{S}$ model in order to help implement the network to share teaching resources. System page of Dreamweaver web page was design software, the background for using SQL Server 2000 database design, the use of ASP, ADO data combined with multimedia data transmission technology for art teaching resources system was realized.
\end{abstract}

\section{General instruction}

With the popularization and development of computer technology and the Internet, network teaching, especially web-based distance learning current government or institutions are very concerned, and is increasing its investment in research and development. The most important part of the network of teaching in the information age is the network teaching information resource management. This paper analyzes the current situation of online teaching, the status of the characteristics of network information resources and network information resources construction, proposed multimedia art information resource system design, the use of database technology, Active Directory technology, www technology, and video-on-demand technology to achieve complete multimedia art information Resource System. The system uses a distributed design, using SQL Serve: large database systems to ensure the performance of the system. At the same time integrated video-ondemand capabilities to watch online video clips; implements WWW client system $\mathrm{C} / \mathrm{S}$ mode server management system, B / S model, in line with the current popular software operating modes, it is conducive to a network of information resources sharing.

Multimedia art information resource management system is only one of the multimedia subsystems. Multimedia art information resource system consists of Fine Arts Library and art materials. Library manager is variety of multimedia material, the use of buffer architecture; multimedia teaching materials database management, direct audit storage architecture. For multimedia video clips, video-on-demand systems integration capabilities, these video clips can be viewed online. The system provides users with a Web browser-based query system, the user can browse through the Web, query, and call the system resources. Meanwhile, the system provides the material library and textbook library management software; you can easily to the Library and manage library materials. Therefore, the development of multimedia art school teaching information resource system is of great significance.

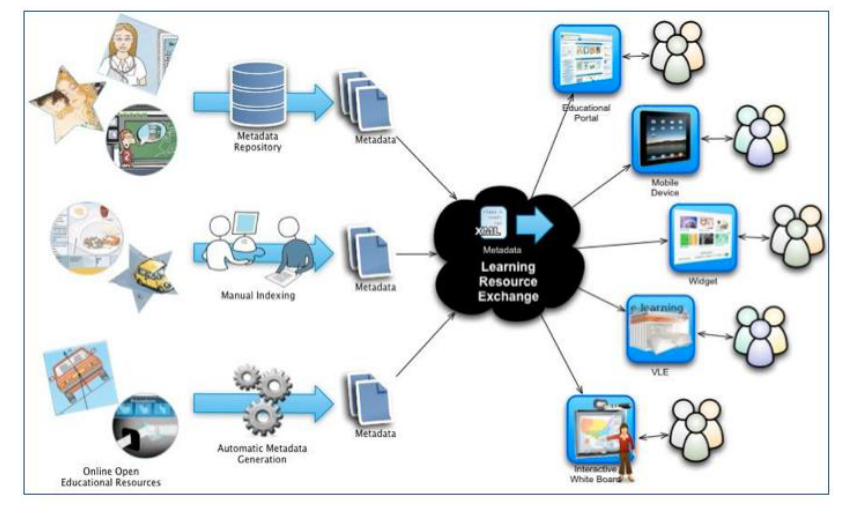

Figure 1: Overview of the Learning Resource Exchange infrastructure

Figure 1. Architecture of art teaching management system

\section{Research status and development trends}

At present, many domestic university teachers according to their teaching needs, develop teaching system has given practical value. Colink After ten years of development, has become well-known domestic and foreign enterprises in the field of education, the product brand "NewClass" known continents, so that millions of teachers and learners to benefit from high-tech products Colink. Based on more than ten years of professional experience in the development and production of teaching equipment accumulated, conform to the needs of foreign language teaching mode continuous reform and development, NewClass new products constantly every year. The company main products are divided into three 
categories: NewClass digital language learning system, NewClass simultaneous interpretation, training systems, NewClass multimedia art teaching system. Guangzhou Jia Hong Electronics Co., Ltd. developed which enables remote control based on the campus network, batch control, remote monitoring (as) intercom, live broadcast, streaming media and other powerful features. Multimedia control system since its launch, users get the praise and praise, and with domestic and foreign companies purchasing agent. With the development of science and technology, multimedia, teaching, online teaching, distance learning, etc. have sprung up across the country.

Guangzhou City, Guangzhou Radio and Television University is facing, the use of computer networks, satellite television networks and telecommunications networks, based on digital technology, multimedia, interactive teaching platform, municipal colleges and universities to carry out modern distance and open education, founded in September 1961, during the Cultural Revolution closed, in January 1979 re-run, in 1985, 4 menstrual approved by the Ministry of Education as a separate provincial TV. The strong support of the Guangzhou municipal government, the City Board of Education, the schools and government information technology investment and modernization of education, have been built with 3000 information points Gigabit backbone campus network system, the coupling distance education broadband network systems 13 campuses digital satellite IP access system, remote two-way video teaching system, electronic examination room network monitoring system and security monitoring systems, online classroom broadcast system, IP courseware production systems, paperless examination centres', remote reception centre, courseware on-demand systems, distance learning platform e-mail system, enrolment management system, student achievement query system, digital library, office automation system

Systems, real-time video and voice interactive system is more than 30 hardware and software applications. Guangzhou TV has become the leading Guangzhou Modern Distance Education of the main force, has become the backbone of the Guangzhou public higher education.

From the above case we can not find more extensive use of multimedia teaching system to the major schools, education is a new round of information technology in education reform appreciation.

In Britain, for example, since 1989, the United Kingdom as a developed country, in the information field of education has a pragmatic visionary and innovative strategic policy on. Over the years, the British use strong comprehensive national strength, give full play to advantages of the parties, and vigorously strengthen the information infrastructure, and actively play to the advantages of information technology education personnel, efforts to develop the use of rich information resources, contributed greatly to the entire community a comprehensive level of information upgrade, British National Learning Network has become Europe's largest education portal, but with powerful search capabilities. It is worth mentioning that the construction of the learning society in the United Kingdom by means of information technology has taken a substantial step. 2000 British "University for Industry ,, the operation of government use of information technology is to enable people to learn the way of revolutionary change, it is through a modern network and communication technology, to supply the needs of learners and various educational resources in a timely manner effectively connected. Industry University Learning Network is made throughout the country, the distribution of the various learning centres constitute reasonable, all kinds of workplaces, colleges, universities, libraries, residential areas, shopping centres, football clubs, leisure centres and so on to be incorporated, it is an open to all, helping individuals and organizations understand their learning needs and to provide the most appropriate learning resources learners new organization, operation and development of the industry has made the University of British Lifelong Learning Society entered a new phase covering Australian National Australian Education Network includes not only all universities, but also cover all primary and secondary schools across Australia, it helps teachers and teaching departments at all levels to share information across Australia and around the world through strong education network, the Australian government for foreign students of the school received a rigorous curriculum and teaching quality control, and management of the curriculum and assessment in the form of legislation. If a school in the assessment or examination unqualified, will be ordered for rectification or even cancelled recruit qualified foreign students. This whole process of quality management and control relies heavily on Australian investment in education network, which ensures the quality of their education, so that it enjoys a good reputation in the international community.

\section{ASP technology introductions}

ASP (full name is the Active Server Pages, meaning: Active Server Pages). When the information needed for Web client sends an instruction by the server-side application requests through a Web server, generate a web page based on information in the database and passed back to the client. ASP is running on the server side, implementation of the results generated dynamically generated pages explain sent to the client browser, and scripting language is interpreted by a Web browser to perform. Because ASP is a server-side interpretation, developers do not have to consider whether the client browser supports ASP, and developers do not have to worry about other people stealing to download the program code, ASP common data link is ADO, ADO (ActiveX Data Object ActiveX Data Objects) technology refers generally be completed in several different programming methods with a specific task.

ADO connection objects can store information in a single session. OLEDB session connection Data Source objects and combinations of objects connection object has a method execution. In addition, the connection may be in 
the command object, and the object is recorded dependency sets.

On JavaScript scripting language instructions is to adapt to create dynamic Web pages, a scripting language, can also apply to the client (browser) can also be used on the server side. JavaScript language created in the beginning to help change the tag on the page to development, so that the client is more abundant, because the page can be used as the target, and DOM structure of the page by using the Java script DOM operation, to interactive web pages, make Web pages and users to achieve real-time interaction, so that the page contains more active elements.

\section{Multimedia art teaching resources management system requirements analysis}

With the continuous development of computer technology, multimedia art teaching has become a new revolution in the field of art education, pay attention to the world. Meanwhile, people on multimedia art teaching requirements are getting higher and higher, audio, video, multimedia teaching has become an indispensable part.

In the traditional art teaching, student learning resources, mainly by teachers prepare learning materials and textbooks composition, slightly less compared to the same learning resources on the network, and since most of these data along with the completion of teaching time and the end, which triggered the student can not reorganization of knowledge at the completion of the job also rely mainly on the brain image storage, knowledge professional art teaching resources website can provide a relatively wide, and most of the teachers through careful organization, also provides links to other related learning resources, students can more easily find the right learning resources, greatly enriched the art of teaching content for the training of students' innovative ability to provide a new way, we can say, building art curriculum resources for classroom teaching art provides rich support knowledge resources, although students are in the classroom, but the network resources gave students the opportunity to transcend the boundaries of time and space, spanning ancient and modern, flying in space history and imagination. Give full play to the role of the outstanding quality of multimedia art teaching resources, teaching resources to ensure the submission of using enough multimedia materials should be submitted to meet the following requirements:

1. Submit all relevant procedures, documentation and materials.

2. The software first needs to go through the installation. Such teaching resources in advance to lie before the downloaded package upload, at the time of submission of resources relevant attributes need to be described.

3. User module using $\mathrm{C} / \mathrm{S}$ mode, after teaching submissions, should pay attention to where the directory structure of the $\mathrm{B} / \mathrm{S}$ mode, the online submission of materials, the same changes in the relative directory structure should be noted. "Flow, technology to manage video data and control solutions to high-speed network transmission congestion caused by dynamic video playback problems can not successfully, to ensure quality and continuous playback, the need for application software VOD service following major technical requirements and aims.

\section{Systems development goals}

Construction art multimedia teaching resources is to show the form of student teaching, better enable students to understand and learn Chinese and foreign art resources, students of art proper aesthetic ideas. The system art resources include: 1 describes the different historical periods and foreign, different genres, different styles of art works of art for students to further study; 2 in chronological order to show the different historical periods, different genres, and different kinds of work. Related multimedia resources are on the one hand to deepen students' understanding of the text description, the other students the right aesthetic ideas to improve the aesthetic ability of students. Students learn to enhance their knowledge. Students and teachers through online communication to increase the interaction of student learning stimulate students 'enthusiasm and interest, through communication between teachers and students, students and students communicate, make it easier for the teacher to understand students' learning progress, learning level and learning ability and so on. We can also discuss works of art, works of art so that students can freely discuss their views on the masterpieces of play, or the lack of information related to teaching resources can be shared; works of art for the moment to discuss the main works of art such as advertising design works or a strong artistic movies, or a certain design competitions freedom to express their views, share their own arguments. Thus, multimedia plays an important role in teaching resources, the network teaching system and its important role in the teaching system play in the design of the system should achieve the following objectives.

Resource classification system enables administrators to efficiently manage the media category management and end-user repository, reasonable or not directly affect the system administrator and end-user management efficiency of resources utilization of resources, so that both are important factor. The system should provide as flexible classification management measures to meet different application of different types of materials and objects classification requirements.

\section{System testing}

System testing is an important stage in the lifetime of the software, is a key step in software quality assurance. More simply, software testing before the software is put into operation, the software requirements analysis, and design specifications and coding of the final review activities. Software Engineering IEEE 1983 proposed term is defined in software testing to the next is: "Use 
manual or automatic means to run or determination process of a software system, which aims to verify that it meets specified needs or understand the expected results difference "between actual results. This definition clearly states: The purpose of software testing is to test the software system meets the needs is to find errors and execution process, in order to prove that the procedure is wrong, rather than proof of program error, a successful test is found so far not Wrong test found. The purpose of software testing determines how to organize the testing. If the purpose of the test, Shandong University, a master's degree thesis was to find errors as much as possible, then the test should be directed towards the more complex part of the software or more before the error location. If the test purpose is to give end users with a certain confidence quality evaluation, then the test should be directly aimed at practical applications often used in commercial assumptions.

Test is mainly based on the mission statement is to develop technical specifications and test system, is testing the principles of integrated test and evaluation software overall functionality and performance is the theoretical basis of software testing activities, test method is to test the practical application of the principles of and access to the side again It means the data. Software-based common for software testing should follow the general principles and methods to test the software. Meanwhile, for the characteristics of the software, you must find the appropriate test methods. Reasonableness test cases for testing and evaluation software plays a key role, and how to make the design of use cases fair, reasonable and typical effectively is not easy. So it should be with the software development staff and end users together, targeted research and described the actual operating environment, the formation of rational methods and techniques of software testing test suite is varied. For software testing technology, can be classified from a different angle: if you need to perform from the perspective of the software under test, the test can be divided into static and dynamic testing. From the internal structure of the test is for a system and the specific algorithm point of view, can be divided into white box and black box testing network. Static testing is the general term for methods of characterization of the test program, the main characteristic of this method is being tested without using a computer running a program, instead of using other means to achieve the purpose of detection. Dynamic testing is actually running the test program, enter the appropriate test, the results of determination to meet the requirements, so that the accuracy of testing procedures, reliability and effectiveness.

\section{References}

1. Zhang filing multimedia technology in teaching applications on the network due to remote Education Supplement, 153 (2000)
2. Pool cloud computer multimedia network technology in the teaching of Liaoning Administration College, 90 (2000)

3. Han Jing. Confront contemporary art education principal institutions of higher art China Forum on -2010. Art Watch, 78(2010)

4. Zhang Jun to stay. On Chinese painting teaching traditional culture. Arts education research, 47(2011)

5. Li Si Hui. On Myth and Art Education of College Students Comprehensive. Heilongjiang Science and Technology Information. 25(2008)

6. Liangtai Sheng. Reform of university teaching of Chinese painting Rethinking. Zong Tai'an College of Education Science, 45(2003)

7. Reflections by Lisa Shuai. Contemporary art trends in China. "Industry and Technology Forum." 2012.

8. Zhang Bing. Explore the aesthetic perspective of Art Education. China-school education, 15(2010) 